DOI 10.12957/demetra.2014.8256

\title{
Uma abordagem sobre a capacidade antioxidante in vitro de alimentos vegetais e bebidas
}

\section{An approach about invitroantioxidant capacity of plant foods and beverages}

Maria de Lourdes Reis Giada'

1 Departamento de Nutrição Básica e Experimental, Centro de Ciências da Saúde. Universidade Federal do Rio de Janeiro. Rio de Janeiro, RJ, Brasil

Correspondência/ Correspondence Maria de Lourdes Reis Giada E-mail:mlgiada@nutricao.ufri.br

\section{Resumo}

O estresse oxidativo leva à formação de compostos potencialmente tóxicos e danosos ao nosso organismo. Esses compostos podem prejudicar nossa saúde, ao aumentarem o risco de doenças cardíacas e degenerativas e contribuírem para o envelhecimento. Contudo, vários estudos epidemiológicos desenvolvidos nas últimas décadas sugerem que o consumo de vegetais e bebidas ricos em antioxidantes naturais pode reduzir a incidência de doenças relacionadas ao estresse oxidativo. Em função disso, vários estudos têm avaliado a capacidade antioxidante in vitro de diferentes alimentos vegetais e bebidas. Porém, diversos fatores podem influenciar na capacidade antioxidante in vitro de uma amostra, particularmente em matrizes complexas como vinho, frutas e outros vegetais, podendo levar a diferenças significativas nos resultados encontrados. Neste trabalho foram abordados os principais fatores que podem influenciar a capacidade antioxidante in vitro de uma amostra. Assim, diferentes testes para diferentes mecanismos podem e devem ser empregados na determinação da capacidade antioxidante in vitro. Além disso, a curva cinética dos antioxidantes da amostra estudada também deve ser traçada, pois permite explicar como os antioxidantes trabalham, além de permitir prever o comportamento dos mesmos em organismos vivos.

Palavras-chave: Antioxidantes Naturais. Estresse oxidativo. Capacidade Antioxidante. Alimentos Vegetais. Bebidas. Métodos Analíticos. 


\section{Abstract}

Oxidative stress leads to the formation of potentially toxic and harmful compounds to our body. These compounds can cause harm to our health by increasing the risk of heart and degenerative diseases, as well as contribution to aging. However, several epidemiological studies conducted in recent decades suggest that the consumption of vegetables and beverages rich in natural antioxidants may reduce the incidence of diseases related to oxidative stress. As a result, several studies have evaluated the in vitro antioxidant capacity of different plant foods and beverages. Yet, several factors may influence the in vitro antioxidant capacity of a sample, particularly in complex matrices such as wine, fruits and other vegetables, and lead to significant differences in the results. In this work, the main factors that may influence the in vitro antioxidant capacity of a sample were addressed. It can be concluded that different tests to different mechanisms still may and should be employed in the in vitro antioxidant capacity determination. Moreover, the kinetic curve of the antioxidants of the studied sample should also be drawn, as it allows to explain how antioxidants work. In addition, it allows to predict the antioxidants behavior in living organisms.

Key words: natural antioxidants; antioxidant capacity; plant foods, beverages; analytical methods.

\section{Introdução}

Sabemos que o estresse oxidativo leva à formação de compostos potencialmente tóxicos e danosos ao nosso organismo, como os radicais livres. Estes, ao agirem sobre componentes celulares vitais, como lipídeos, proteínas e DNA, podem prejudicar a saúde humana, aumentando o risco de doenças cardíacas e degenerativas e contribuindo para o envelhecimento. ${ }^{1,2,3}$ Contudo, vários estudos epidemiológicos desenvolvidos nas últimas décadas sugerem que o consumo de vegetais e bebidas ricos em antioxidantes naturais pode reduzir a incidência de doenças relacionadas ao estresse oxidativo. ${ }^{4}$

A atividade ótima dos antioxidantes naturais se deve à estrutura química dessas substâncias. Nos flavonoides, por exemplo, a atividade antioxidante se relaciona com a presença de grupos hidroxil nas posições 3' e 4' do anel B, os quais conferem elevada estabilidade ao radical formado, participando no deslocamento do elétron, e uma dupla ligação entre os carbonos $\mathrm{C}_{2} \mathrm{e}_{3}$ do anel $\mathrm{C}$ 
em conjugação com o grupo carbonilo na posição $\mathrm{C}_{4}$, o qual torna possível o deslocamento de um elétron do anel B. Adicionalmente, grupos hidroxil livres na posição 3 do anel C e na posição 5 do anel A, juntamente com o grupo carbonilo na posição 4, também são importantes para a atividade antioxidante desses compostos (figura 1). A quercetina, um flavonoide encontrado em quantidades elevadas na cebola, chá e maçã, reúne todas essas características e é um dos antioxidantes naturais mais potentes conhecidos. ${ }^{5}$

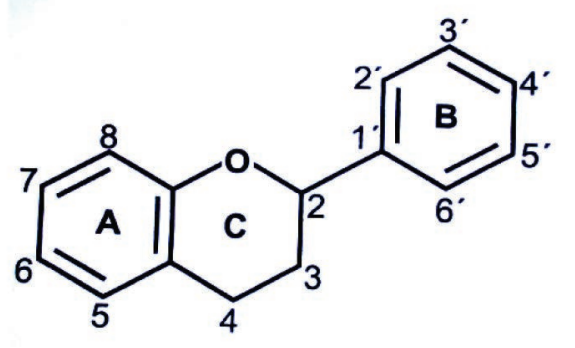

Figura 1. Estrutura química básica e sistema de numeração dos flavonoides.

Quanto ao mecanismo de ação, vários antioxidantes naturais podem agir tanto como antioxidantes primários ou sequestradores de radicais livres, quanto como secundários ou de prevenção. ${ }^{6}$ Os antioxidantes primários atuam removendo os radicais livres do nosso organismo, pela interrupção da reação em cadeia provocada por estes através da doação de um átomo de hidrogênio para o radical (figura 2). Devido a sua conformação molecular, os radicais fenoxilo formados são intermediários bastante estáveis e não iniciam facilmente uma nova reação em cadeia. Esses radicais atuam reagindo com outros radicais livres, bloqueando as reações de propagação da oxidação. ${ }^{7}$

$$
\begin{aligned}
& R O O^{\circ}+\mathrm{AH} \rightarrow \mathrm{ROOH}+\mathrm{A}^{*} \\
& R O 0^{\circ}+\mathrm{A}^{*} \rightarrow \mathrm{ROOA}
\end{aligned}
$$

Figura 2. Mecanismo de ação dos antioxidantes primários ou sequestradores de radicais livres. 
Os antioxidantes secundários podem atuar por meio de numerosos mecanismos, reduzindo ou retardando a taxa de iniciação da oxidação por sua ação no bloqueio da decomposição dos peróxidos e hidroperóxidos. Como supressores de oxigênio singlete, os antioxidantes secundários captam a energia do oxigênio singlete $\left({ }^{1} \mathrm{O}_{2}\right)$, que volta ao estado fundamental $\left(\mathrm{O}_{2}\right)$. Como quelantes de íons metálicos, esses antioxidantes são capazes de interagir e desativar íons metálicos que catalisam reações de peroxidação lipídica. ${ }^{8}$

Em função disso, vários estudos têm avaliado a capacidade antioxidante in vitro de diferentes alimentos vegetais e bebidas. ${ }^{9,10,11}$ No entanto, diversos fatores podem influenciar na capacidade antioxidante in vitro de uma amostra, podendo levar a diferenças significativas nos resultados encontrados.

Principais fatores que podem influenciar a capacidade antioxidante in vitro

\section{Procedimento de isolamento e pureza da substância}

Devido à grande diversidade química existente, os antioxidantes são difíceis de se separar e quantificar individualmente em matrizes biológicas. ${ }^{12}$ Por outro lado, sabemos que combinação de antioxidantes (sinergia) nos alimentos é mais eficaz do que a soma dos efeitos individualmente. Em função disso, vários estudos têm avaliado a capacidade antioxidante total de diferentes amostras biológicas, particularmente em matrizes complexas, como vinho, frutas e outros vegetais. No entanto, aminoácidos e outros constituintes não antioxidantes dessas matrizes, como os ácidos urônicos, podem superestimar os resultados obtidos. ${ }^{13}$

\section{Tipo e polaridade do solvente empregado na extração}

Para se separar as substâncias apolares das polares, que apresentam atividade, torna-se necessário fazer a escolha correta dos solventes. Contudo, os principais antioxidantes naturais são a vitamina C e a maioria dos compostos fenólicos (flavonoides, taninos, cumarinas e ácidos fenólicos), classificados como antioxidantes hidrofílicos, além dos carotenoides e vitamina E, classificados como antioxidantes lipofílicos. Assim, a solubilidade dessas substâncias também está diretamente relacionada à natureza do solvente empregado na sua extração. ${ }^{14}$ Devido a isso, a capacidade antioxidante in vitro de uma amostra pode apresentar diferenças significativas pelo mesmo método em diferentes solventes, pois seus antioxidantes podem não se comportar da mesma forma em todos os solventes empregados, estabelecendo diferentes interações com os mesmos. ${ }^{15}$ 
Assim, em qualquer ensaio de capacidade antioxidante, os resultados devem ser medidos em extratos ou soluções, bem como relacionados a uma curva de calibração, no mesmo solvente. Em nossos estudos, em função da característica das amostras e antioxidantes naturais estudados, adotamos a extração sequencial com solventes de diferentes polaridades ${ }^{16}$ (figura 3).

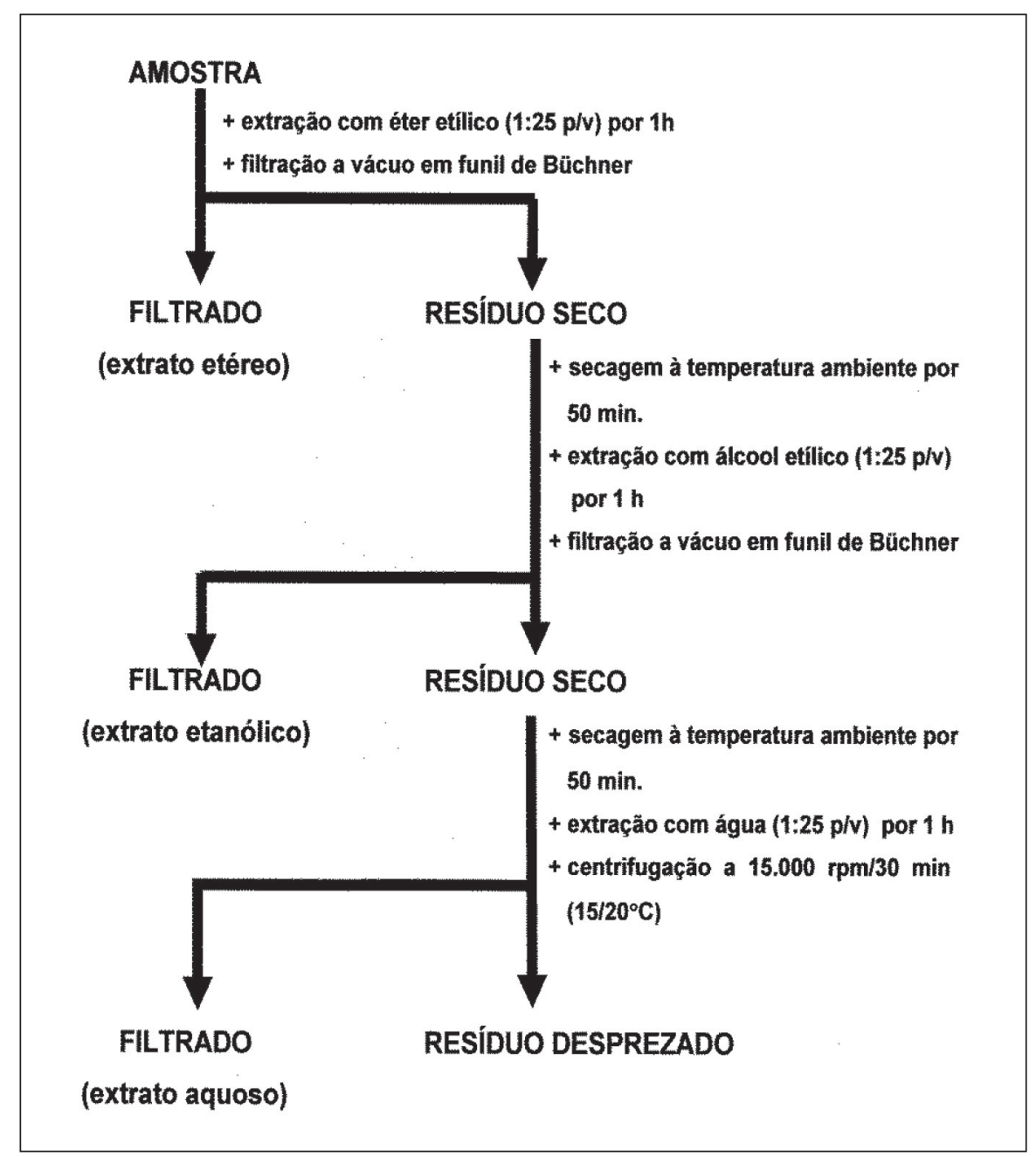

Figura 3. Extração sequencial com solventes de diferentes polaridades. 
Nesta técnica, primeiramente é efetuada a extração com o éter etílico (solvente de mais baixa polaridade). Em seguida, o resíduo da primeira extração é seco e extraído com álcool etílico (solvente de média polaridade). Finalmente, o resíduo da segunda extração também é seco e extraído com água (solvente de mais alta polaridade). Nossos resultados mostraram um mais alto teor de resíduo seco no extrato etéreo, indicando maior presença de compostos de baixa polaridade neste extrato. Mais especificamente, os lipídios presentes em quantidades elevadas nas amostras estudadas.

\section{Sistema de teste antioxidante}

Até o momento, ainda não existem métodos aprovados ou padronizados para determinação da capacidade antioxidante. Os métodos usados para determinação da capacidade antioxidante in vitro são ensaios que envolvem diferentes mecanismos do sistema de defesa antioxidante do nosso organismo, podendo ser divididos em dois grupos: métodos baseados na remoção de radicais livres do meio e métodos que empregam lipídeos como substrato. Os métodos baseados na remoção de radicais livres do meio envolvem a geração de diferentes radicais, agindo através de uma variedade de mecanismos, bem como a medida de uma gama de produtos finais, em tempo fixo ou sobre um intervalo de tempo. ${ }^{17}$

Entre os métodos que empregam lipídeos como substrato, a grande diversidade de métodos analíticos (químicos, físicos e/ou físico-químicos) existentes também coloca algumas dificuldades de seleção do método mais adequado para determinado estudo de avaliação da capacidade antioxidante. ${ }^{18}$ Dependendo do sistema em que os antioxidantes foram avaliados (aquoso ou lipídico), compostos modelos mostraram-se fortemente antioxidantes em um método e pró-oxidante em outro. ${ }^{19}$ Observou-se também o chamado "paradoxo polar", onde antioxidantes hidrofílicos apresentaram-se mais efetivos do que os lipofílicos em volumes elevados de óleo, enquanto antioxidantes lipofílicos apresentaram maior atividade em emulsões. ${ }^{20}$

\section{Substrato a ser protegido}

De acordo com o método usado, diferentes substratos são empregados na medição da ação protetora dos antioxidantes contra a oxidação lipídica. Óleos como os de girassol, soja, oliva e palma são comumente usados como substratos em sistemas lipídicos. Da mesma forma, lipossoma e microssoma são empregados em sistemas semelhantes às condições práticas in vivuo, devido à similaridade entre a composição da membrana lipídica e aquela das membranas biológicas. A LDL humana, simulando a inibição da oxidação de lipoproteínas de baixa densidade no plasma 
sanguíneo depois da administração oral dos antioxidantes, também é usada como substrato. ${ }^{21}$ De acordo com a natureza do substrato a ser protegido pelos antioxidantes, diferenças significativas podem ser encontradas na capacidade do antioxidante in vitro da amostra estudada.

\section{Principais métodos antioxidantes}

Entre os métodos baseados na remoção de radicais livres do meio, os que têm sido mais usados na determinação a capacidade antioxidante in vitro são o ensaio do poder antioxidante pela redução férrica (FRAP), ensaio do radical 2,2-difenil-1-picrilhidrazil (DPPH), ensaio de descoloração do radical ABTS e ensaio da capacidade de absorção do radical oxigênio (ORAC). Entre os métodos que empregam lipídeos como substrato, têm se destacado o sistema $\beta$-caroteno ácido linoleico, o ensaio das substâncias reativas ao ácido tiobarbitúrico (TBARS) e a LDL humana.

A capacidade antioxidante in vitro pode e deve ser avaliada com diferentes testes para diferentes mecanismos. Todavia, a diversidade das condições de ensaio e dos sistemas modelos usados para determinação da capacidade antioxidante tem gerado algumas dificuldades no que diz respeito a interpretação e comparação dos resultados obtidos através dessas metodologias. Apesar disso, o TROLOX (um análogo hidrossolúvel da vitamina $\mathrm{E}$ ) pode ser usado como antioxidante padrão nos diferentes métodos. ${ }^{22}$ Desta forma, para efeito de comparação, os resultados dos diferentes métodos podem ser expressos em equivalentes de TROLOX.

\section{Importância do estudo cinético}

O estudo cinético dos antioxidantes da amostra analisada é importante, uma vez que permite elucidar os pormenores do comportamento dessas substâncias. Primeiramente, este estudo ajuda a explicar como os antioxidantes trabalham. Em complemento, permite prever o comportamento dessas substâncias em organismos vivos. ${ }^{23}$ Portanto, a partir das leituras obtidas durante a determinação da capacidade antioxidante in vitro, pode-se traçar a curva cinética dos antioxidantes da amostra e avaliar, a partir disso, a eficácia dos mesmos para a análise em intervalos de tempo variáveis.

A figura 4 mostra, respectivamente, as curvas cinéticas da capacidade antioxidante do extrato etanólico e extrato aquoso de uma amostra, comparados ao TROLOX e BHT como padrões, no método ORAC. 


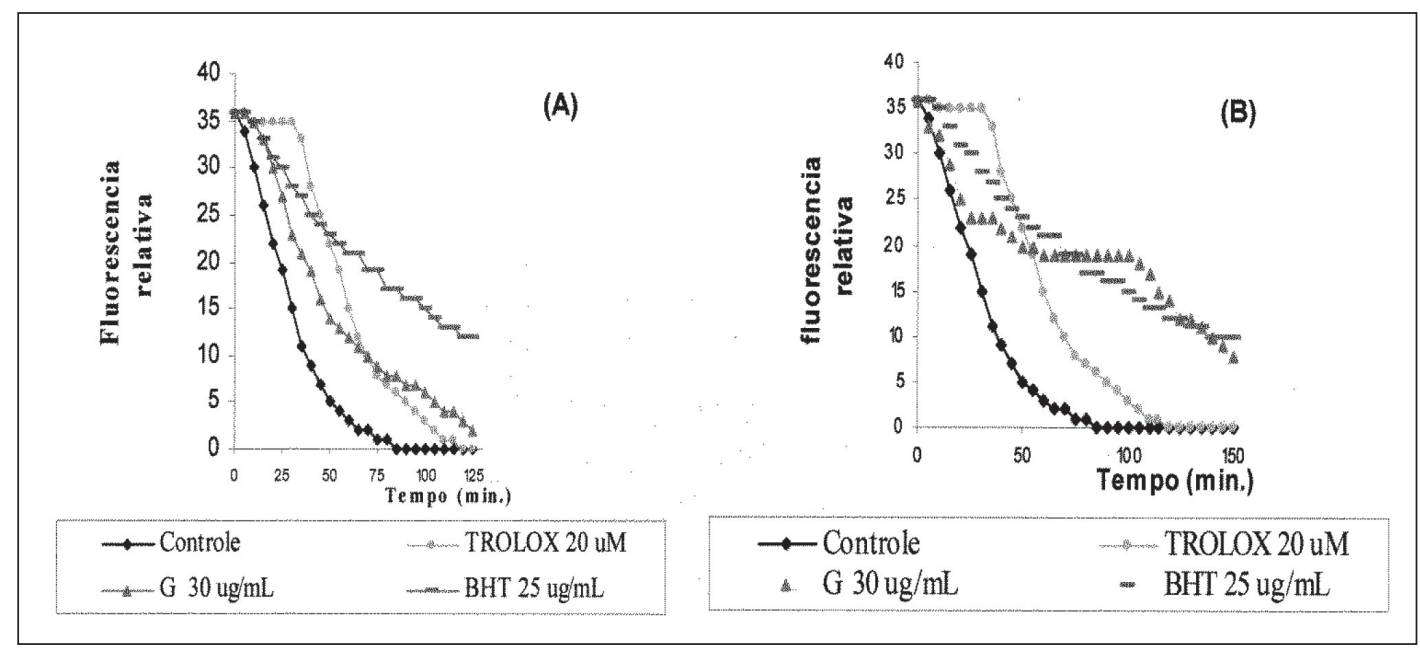

Figura 4. Curva cinética da capacidade antioxidante do A) extrato etanólico e B) extrato aquoso de uma amostra, comparados ao TROLOX e BHT como padrões, no método ORAC (Controle - sem antioxidante, G - amostra).

Conforme se pode ver na figura 4, cada amostra apresentou comportamento distinto no ensaio OAC. Nas concentrações estudadas, o padrão TROLOX apresentou a maior capacidade antioxidante entre as amostras nos primeiros 50 minutos de ensaio. Porém, após esse tempo, a capacidade antioxidante do TROLOX decaiu rapidamente. O extrato aquoso apresentou forte capacidade antioxidante comparado ao etanólico durante todo o ensaio. Entretanto, em relação ao BHT, a capacidade antioxidante do extrato aquoso ficou abaixo deste nos primeiros 65 minutos, permaneceu constante entre 65 e 100 minutos e passou a ser maior do que a do BHT entre 85 e 100 minutos. Após esse tempo, a capacidade antioxidante do extrato aquoso volta a decair.

\section{Conclusão}

Tendo em vista todos os fatores que podem influenciar a capacidade antioxidante in vitro de uma amostra, a seleção do método mais adequado para esta medida deve ser criteriosamente considerada. Diferentes testes para diferentes mecanismos podem e devem ser empregados. Contudo, para efeito de comparação dos resultados obtidos nos diferentes métodos, os mesmos podem ser expressos em equivalentes de TROLOX.

A curva cinética dos antioxidantes da amostra também deve ser traçada, pois permite explicar como os antioxidantes trabalham, além de permitir prever o comportamento dos mesmos em organismos vivos. 


\section{Referências}

1. Becher EM, Nisse LR, Skibsted LH. Antioxidant evaluation protocols: food quality or health effects. Eur. Food Res. Technol. 2004; 219(6):561-571.

2. Hallwell B, Murcia MA, Chirico S, Aruoma OI. Free radicals and antioxidants in food and in vivo: What they do and how they work? Crit. Rev. Food Sc. Nutr. 1995; 35 (1-2):7-20.

3. Temple NJ. Antioxidants and disease: More questions than answers. Nutrition Research. 2000; 20(3):449-459.

4. Hollman PCH. Evidence for health benefits of plant phenols: local or systemic effects? J. Sc. Food Agric. 2001; 81(9):842-852.

5. Sánchez-Moreno C. Compuestos polifenólicos: efectos fisiológicos, actividad antioxidante. Alimentaria. 2002; 38(329):29-40.

6. Shahidi F, Naczk M. Phenolics in food and nutraceuticals. Boca Raton: CRC Press; 2004.

7. Shahidi F, Janitha PK, Wanasundara PD. Phenolic antioxidants. Critical Reviews in Food Science and Nutrition. 1992; 32(1):67-103.

8. Chaillou LL, Nazareno MA. New method to determine antioxidant activity of polyphenols. J. Agric. Food Chem. 2006; 54(22):8397-8402.

9. Duthie GG, Duthie SJ, Kyle AM. Plant polyphenols in cancer and heart disease: implications as nutritional antioxidants. Nutr. Res. Ver. 2000; 13(1):79-106.

10. Oliveira AC, Valetim IB, Goulart MOF, Silva CA, Bechara EJH, Trevisan MTS. Fontes vegetais naturais de antioxidantes. Química Nova. 2009; 32(3):689-702.

11. Scalbert A, Williamson G. Dietary intake and bioavailability of polyphenols. J. Nutr. 2000; 130 (8 Supl): 2073S-2085S.

12. Prior RL, Cao G. Analysis of botanicals and dietary supplements for antioxidant capacity: a review. J. AOAC Int. 2000; 83(4):950-956.

13. Naczk M, Shahidi F. Phenolics in cereals, fruits and vegetables: occurrence, extraction and analysis. J. Pharm. Biomed. Anal. 2006; 41(5):1523-1542.

14. Huang D, Ou B, Hampsch-Woodill M, Flanagan JA, Deemer EK. Development and validation of oxygen radical absorbance capacity assay for lipophilic antioxidants using randomly methylated $\beta$-cyclodextrin as the solubility enhancer. J. Agric. Food Chem. 2002; 50(7):1815-1821.

15. Pérez-Jiménez J, Saura-Calixto F. Effect of solvent and certain food constituents on different antioxidant capacity assays. Food Res. Int. 2006; 39(7):791-800.

16. Giada MD, Mancini-Filho J. Antioxidant capacity of the striped sunflower (Helianthus annuus L.) seed extracts evaluated by three in vitro methods. Int. J. Food Sci. Nutr. 2009; 60(5):395-401.

17. Re R, Pellegrini N, Proteggente A, Pannala A, Yang M, Rice-Evans C. Antioxidant activity applying an improved ABTS radical cation decolorization assay. Free Radic. Biol. Med. 1999; 26(9-10):1231-1237. 
18. Silva EL, et al. Inhibitory effect of quercetin metabolites on rat plasma lipid peroxidation. In: Meetingeting of South American Group for Free Radical Research. Abstracts; 1999; Florianópolis, Brasil. Florianópolis: CCB/UFRSC, 1999. p.155.

19. Von Gadow A, Joubert E, Hansmann CF. Comparison of the antioxidant activity of Aspalathin with that of other plant phenols of rooibos tea (Aspalathus linearis), $\alpha$-tocopherol, BHT and BHA. J. Agric. Food Chem. 1997; 45(3):632-638.

20. Moure A, Cruz JM, Franco D, Dominguez JM, Sineiro J, Dominguez H, et al. Natural antioxidants from residual sources. Food Chemistry. 2001; 72(2):145-171.

21. Frankel EN, Meyer AS. The problems of using one-dimensional methods to evaluate multifunctional food and biological antioxidants. J. Sc. Food Agric. 2000; 80(13):1925-1941.

22. Huang D, Ou B, Prior RL. The Chemistry behind antioxidant capacity assays. J. Agric. Food Chem. 2005; 53(6):1841-1856.

23. Giada MRL. Antioxidant capacity of the striped sunflower seed (Helianthus annuus L.) aqueous extract. Eur. J. Lipid Sc. Technol. 2008; 110(3):284-290.

Recebido: $24 / 11 / 2013$

Aprovado: 16/12/2013 